\title{
The Impact of Health Promotion on Healthy Behavior Viewed from Health Beliefe Model Perspective (Study in Kediri Regency, East Java Province)
}

\author{
Nurwulan Andadari ${ }^{1}$, Andarini Andarini², Soemarno Soemarno ${ }^{3}$, Edi Widjajanto ${ }^{2}$ \\ ${ }^{1}$ Postgraduate Environmental Sciences Doctoral Program, University of Brawijaya, Malang, Indonesia \\ ${ }^{2}$ Faculty of Medicine, University of Brawijaya, Malang, Indonesia \\ ${ }^{3}$ Faculty of Agriculture, University of Brawijaya, Malang, Indonesia
}

Email address:

nurwulanandadari99@gmail.com (N. Andadari)

*Corresponding author

\section{To cite this article:}

Nurwulan Andadari, Andarini Andarini, Soemarno Soemarno, Edi Widjajanto. The Impact of Health Promotion on Healthy Behavior Viewed from Health Beliefe Model Perspective (Study in Kediri Regency, East Java Province). International Journal of Health Economics and Policy. Vol. 4, No. 4, 2019, pp. 110-121. doi: 10.11648/j.hep.20190404.11

Received: September 9, 2019; Accepted: October 4, 2019; Published: October 25, 2019

\begin{abstract}
Health promotion or health promotion is an important effort that must be done by health workers in collaboration with the community to create a healthy community both physically and mentally, especially in achieving the Healthy Indonesia target. But until now health promotion in Indonesia has not reached the maximum stage. There are still many people who are not health conscious. Preventing better than cure is also still a motto and cannot yet become a foundation of awareness in the community. If these constraints are not immediately found a solution, then it will gradually have an impact on the erosion of healthy living behavior of the community. In fact, the real form of this threat is the increase in mortality. The danger of this death will be more dangerous if it threatens pregnant women, because the threatened soul is not only the soul of a mother, but also her baby. Regarding these problems, the study was conducted to examine the impact of health promotion on healthy behavior in terms of the perspective of health beliefs. A positivist or scientific approach using SEM-AMOS analysis techniques. The data used are primary data distributed to 100 respondents. The results of this study indicate that Health promotion has a significant effect on perceived susceptibility, perceived severity, perceived benefits and perceived barriers. Perceived susceptibility and Perceived benefits have no significant effect on cues to action. While perceived severity \& perceived barriers have a significant effect on cues to action, then Cues to action has a significant effect on self efficacy.
\end{abstract}

Keywords: Health Promotion, Healthy Life Behavior, Health Belief Model, Maternal Mortality Rate, Infant Mortality Rate

\section{Preliminary}

Health promotion or health promotion is an important effort that must be done by health workers together with the community to create a healthy community both physically and mentally specifically in achieving the Healthy Indonesia target. Until now, health promotion in Indonesia has not yet reached maximum success. There are still many people who are not health conscious. Preventing more than treatment is also still a motto and cannot yet become the basis of awareness in the community [4].

This condition can be caused by several things, where the first is due to the lack of health workers so that the human resources to conduct health promotion such as Home Care, counseling, and demonstrations are also limited, especially in remote areas in Indonesia. Both Indonesians still believe in myths. For example, if there are people who are sick, it is better to be brought to the shaman than to be examined by a health professional or if there is a sick person, it will be associated with mystical things such as witchcraft, spirits and so on. This is the biggest problem in carrying out health promotion. The mindset of people who are close to myths, often makes it difficult for people to receive health education given by health experts. This is culture and to change culture also cannot be revolutionary but must be slow.

If the above constraints are not immediately found a 
solution, then it will gradually have an impact on the erosion of healthy living behavior of the community. In fact, the real form of this threat is the increase in mortality. This has apparently been read by all regions in Indonesia, Kediri Regency is no exception. From 2014 to 2016 the health promotion program has not been able to run optimally so that the target to reduce the death rate of the community, especially mothers and infants, has not been fulfilled.

As proof, throughout 2017 the stillbirth rate was 2.8 per 1,000 live births with a total of 4,293 births (9 stillbirth babies). While the AKB of the city of Kediri is 2 per 1,000 live births [2].

For under-five mortality rates, based on recording and reporting from community Health centers that have been collected and using the formulation obtained under-five mortality rates per 1,000 live births, the number of under-five deaths is 28 , with details of neonatal deaths 18 , infant deaths 9 and child deaths toddlers 1 of 4,305 live births While in the maternal mortality rate, in 2017 there were no maternal and maternal deaths while postpartum maternal deaths were 4 out of 4293 live births [2].

Therefore, the government through the health department launched an effort to promote health through the Family Care Movement program with the aim of accelerating nutrition and maternal and child health improvement that focuses on the first 1000 days of life, for that all relevant agencies both government and private sector make protective efforts, promotion and support for AKI and AKB reduction acceleration programs. This program ensures all the participation of all parties to contribute to health issues, especially maternal and child health. So hopefully AKI and AKB can go down significantly [13].

Other health promotion programs carried out by the government of Kediri Regency are conducting various activities such as integrated and quality ANC (Ante Natal Care), SMS gateaway, referral program for high-risk pregnant women to hospitals, partnerships of midwives and traditional birth attendants (guidance of traditional birth attendants), and $\mathrm{KB}$ post copy. For reproductive health activities, PPIA (Prevention of HIV Transmission from mother to child), and IVA (Visual Acetate Acid Inspection) have been carried out by all community Health centers [7].

This is in accordance with the theory of health promotion stated in the Charter of Ottawa Charter (1986) which states that Essentially the Basic Thought of Health Promotion is an activity to convey health messages to the public, groups or individuals. There are many health problems found in Kediri Regency, including the emergence of Extraordinary Events which are closely related to the behavior of the community itself, for example the maternal mortality rate and infant mortality rate [22].

To be able to find out whether the health promotion efforts are able to change the behavior of the community amidst the grip of trust and regional culture, then in this study will use PRECEDE-PROCEED as one of its grand theories. PRECEDE-PROCEED is the theory of behavior change that is best used for planning, implementing, and evaluating health promotion in a community or community. This model was developed by Lawrence Green and Kreuter in 1992, and comes from Johns Hopkins University. This model is used to determine the effectiveness of a promotion program or health intervention [16].

The author realizes that behavioral change cannot occur only by carrying out administrative processes by providing education and making regulations only, then the next writer will elaborate the health promotion theory with the Healh Belief Model theory which is a theory of health behavior change and psychological models used to predict health behavior by focusing on individual perceptions and beliefs about an illness. According to this theory, individual behavior is influenced by the perception and belief of the individual itself regardless of whether his perception and belief are in accordance with reality. In this case it is very important to be able to distinguish objective and subjective health assessments [18].

The results of the elaboration of these two theories, which are supported by elements of belief and culture, are believed to be novelty research that have not previously been studied by other studies in the same context and object. In the phenomena and problems that have been described above, it appears that health promotion has an influence on the components of the health belief model where this is supported by research conducted by Ersin \& Bahar which states that after a literature review, it can be seen that experimental research comparing the concept of Health Belief Model (HBM) and Health Promotion Model (HPM) before and after surgery and show the influence of these concepts on education and the limitations of actions taken by nurses. Randomized controlled studies comparing the concepts of HBM and HPM before surgery and post surgery and show the efficiency of interventions can be useful in evaluating the efficiency of interventions [8].

Referring to the phenomena and background of the problems that have been described above, the authors feel that research on the impact of health promotion on healthy living behavior is viewed from the perspective of an important health belief model.

\section{Theoretical Study}

\subsection{Health Belief Model}

The health belief model is a model that is used to describe an individual's belief in healthy living behaviors, so that individuals will engage in healthy behaviors. These healthy behaviors can be in the form of preventive behavior or the use of health facilities. This health belief model is commonly used to predict preventive health behaviors and also behavioral responses to the treatment of patients with acute and chronic diseases. But recently the theory of the Health belief model is used as a prediction of various health-related behaviors [19].

The Health Belief Model (HBM) is the theory most often used in the analysis of changes in health behavior. This 
theory asserts that generally a person's behavior depends on the level of importance that is thought to enable one to achieve a goal. The intended purpose is to avoid health problems with potential severity [5].

The Health Belief Model (HBM), developed by Becker and Maiman 1975, has a role in explaining self-care activities that have a focus on behavior related to disease prevention. The basis of the Health Belief Model (HBM) is an effort so that individuals can take action to prevent, control, or treat health problems if they feel the problem is getting worse; If they feel that the action will produce or produce the expected results; And because of the negative consequences of therapy [1].

The theory of health belief model developed to answer health problems that have been sought optimally from various parties but were less successful. The main concept of the Health Belief Model (HBM) theory is that healthy behavior is determined by individual beliefs or perceptions about the disease and the means available to avoid the onset of the disease. There are four main perceptions that build the Health Belief Model (HBM) theory, each perception individually or in groups that can be used to explain healthy behavior. In its development, other formers were added to the Health Belief Model (HBM), so that the Health Belief Model (HBM) model was expanded to include, modifying factors, cues to action and self-efficacy [19].

\subsection{Health Belief Model Dimension}

The development of the Health Belief Model (HBM) grew rapidly with success that was limited to a variety of Public Health Service programs in the 1950s. When an individual acts to fight or treat a disease, there are four additional two key variables that experts have recently revealed involved in the action, namely perceived vulnerability to an illness, perceived seriousness, benefits received and obstacles experienced in action fight the disease, and the things that motivate these actions. Where the components are mentioned below [9]:

\section{a) Perceived Susceptibility}

Perceived Susceptibility is one of the stronger perceptions in encouraging people to adopt healthy behaviors. The greater the perceived risk, the greater the likelihood of engaging in behavior to reduce risk.

b) Perceived Saverity

Perceived Severity relates to individual beliefs / beliefs about the seriousness or severity of the disease. The perception of seriousness is often based on medical information or knowledge. It can also come from a person's belief that he will get into trouble due to illness and will make or have an effect on his life in general.

\section{c) Perceived Benefits}

Perceived Benefit is related to the benefits that will be felt if you adopt the recommended behavior. In other words, perceived benefit is someone's perception of the value or usefulness of a new behavior in reducing the risk of disease.

d) Perceived Barriers

Because behavior change is not something that can happen easily for most people, another element of the health belief model theory is the problem of perceived obstacles to change. This relates to the individual's own evaluation process for the obstacles faced to adopt new behaviors. Perceptions of perceived obstacles will be a significant element in determining whether behavior changes occur or not. Regarding the new behavior to be adopted, one must believe that the benefits of the new behavior outweigh the consequences of continuing the old behavior. This allows obstacles to be overcome and new behaviors to be adopted.

e) Cues to Action

Cues to Action is a signal to act. The health belief model shows behavior that is also influenced by cues to act. Cues for action are events, people, or things that move people to change their behavior. This gesture for action can come from information from the mass media, advice from people around you, personal or family experiences, articles, etc [16].

f) Self-Efficacy

Self-efficacy is a self-assessment, whether it can do good or bad actions, right or wrong, can or can not do as required. Self-efficacy is different from aspiration (ideals), because the ideals describe something that should be ideal (can be achieved), while self-efficacy describes the assessment of self ability.

\subsection{Health Promotion}

The term Health Promotion is actually a redefinition of health education in public health sciences which is considered capable of accommodating the complexity of existing health problems. The general definition which is the main reference as defined by the World Health Organization "Health Promotion is the process of enabling people to increase control over, and improve their health. To reach a state of complete physical, mental and social, well being an individual or group must be able to identify and realize aspirations to satisfy needs, and to change cope with the environment" [16].

Health Promotion is in an important position, this can be seen from the scope of health promotion according to Dachroni, the scope of health promotion, among others [6]:

a) Counseling (Information Communication) where counseling is a form of intervention carried out to the community to influence knowledge, especially about health, which is carried out through effective communication and delivery of health information that supports changes in the subject's health behavior.

b) Health education (behavior change), within the normative framework of LW Green in Dachroni, an expert from the University of British Columbia, provides a fairly clear definition that distinguishes health education and health promotion, where health education is various combinations of planning and material design activities (interventions) to encourage voluntary adaptation of conclusive health behaviors. While health promotion is a combination of organizing education, policies and regulations for expected behavioral and environmental changes. 
c) Organizing, Empowerment, Community Mobilization (Community, Development, Community Organization). This scope stimulates people to be able to self-establish themselves and not get full intervention from the government. Through organizing, mobilizing and empowering the community, they can recognize, analyze and overcome problems in their environment so that dependencies that have been seen are no longer visible in the community.

d) Health policy, health promotion as a key holder of increasing the degree of public health is expected to be able to establish various regulations and policies that support promotive and preventive efforts, especially in terms of health financing and distribution of health workers who support the efforts mentioned above. Because the Promotive and Preventive orientation no longer refers to the physical development of health facilities and puts forward curative efforts but this shift makes resources the most important change in the status, degree and perception of public health.

e) Social Marketing, this is temporarily touted and is considered the most effective for a while where it continues to carry out campaigns and outreach to all levels of society, society and all sectors to stimulate the mindset of all elements that health is not only the problem of the government, but also the problem of all of us.

f) Protection against the threat of disease (Disability Protect), efforts to reinforce prevention directly such as immunization and others.

g) Efforts to increase (Promotive), and prevent the risk of disease (disability preventive) is a major issue in health promotion campaigns this effort can be done especially in changes in knowledge, attitudes and actions.

h) Health promotion as a combination of planned and educational mechanisms, politics, environment, regulations, and organizational mechanisms that support actions and living conditions that are conducive to the health of individuals, groups and communities. Health promotion is an effort to improve the ability of the community through learning from, by, for and with the community, so that they can help themselves, and develop activities that are supported by community resources, in accordance with local socio-culture, and supported by public health-oriented public policies.

\subsection{Changes in Behavior in Health Promotion}

PRECEDE-PROCEED is the theory of behavior change that is best used for planning, implementing, and evaluating health promotion in a community or community. This model was developed by Lawrence Green and Kreuter in 1992, and comes from Johns Hopkins University. This model is used to determine the effectiveness of a promotion program or health intervention [16].

There are 9 phases in this model, namely social assessment, epidemiological assessment, behavioral and environmental assessment, educational and organizational assessment, administrative and policy assessment, implementation, process evaluation, impact evaluation, and outcome evaluation. Phase 1-5 focuses on planning called PRECEDE stands for Predisposing, Reinforcing, Enabling, Constructs in, Educational / Ecological, Diagnosis, Evaluation, while phases 6-9 focus on implementation and evaluation called PROCEED stands for Policy, Regulatory, Organizational, Constructs in, Educational, Environmental, Development. Gradually, the process leads to the creation of a program, program delivery, and program evaluation [10].

The PRECEDE-PROCEED theory is effective if the problem is taken directly from the community, the intervention is planned, sourced from the data, the type of intervention is feasible and acceptable, includes several program strategies that are carried out continuously, and relies on feedback and evaluation. The whole program is difficult to apply to certain groups, so some communities need to be assessed based on their needs and priorities. The purpose of this model is to identify the best way to promote an intervention by conducting a local needs assessment and program evaluation [10]

\section{Research Methods}

\subsection{Research Approach}

This study uses a positivist or scientific approach, because this study aims to identify causal relationships that describe the behavior patterns of elements in organizations and to test existing theories by developing research hypotheses. As stated by Popper, the positivist approach has two characteristics, namely emphasizing general theory in special cases; and the existence of clear demarcation criteria, so that it emphasizes what can be measured, not what can be observed [12].

\subsection{Sample Collection Method}

The population in this study were all pregnant women and all those related to pregnant women both their families, the surrounding community and health workers in the scope of hospitals, health centers or pomegranate midwife practices in Kediri Regency. Quantitatively it cannot be mentioned in this study. Considering the research population is diverse and is related to pregnant women who step into the final trimester in various hospitals in Kediri Regency and are registered in government hospitals (Regional Public Hospital Kediri Regency) and private hospitals (HVA Hospital, Amelia Hospital, Siti Khotijah Hospital and Aura Syifa Kediri Hospital), community Health centers and pomegranate midwives, so the chosen sampling is cluster sampling (area sampling). Technically, each hospital collected data on the number of women giving birth, and carried out proportional sampling so that the sampling technique used was proportional cluster random sampling. The number of questionnaires to be distributed 
was 100 questionnaires

\subsection{Data Collection Technique}

The data collection method in this study is a survey method, which is a data collection method based on questions raised to respondents designed to obtain information from respondents. Thus, in this study data collection will be carried out through the delivery of questions that must be answered by the respondents who became the study sample.

\subsection{Data Analysis Technique}

The modeling in this research analysis is using SEM (Structural Equation Modeling). According to Santoso, SEM is "a multivariate statistical technique which is a combination of factor analysis and regression analysis (correlation), which aims to examine the relationships between variables in a model, be it between indicators with their constructs, or relationships between constructs". Data processing and analysis in this study, carried out using AMOS version 20 [20].

In the initial phase the test results will be presented using the initial research model, if in the initial model there are still invalid constructs, the elimination process can be carried out. After eliminating the model, the researcher can still modify the developed model, if it turns out that the resulting estimation has a large residual [20].

However, modifications can be made if the researcher has a strong theoretical justification, because SEM is not intended to produce a theory but to test a model that has a correct theoretical footing. Therefore, to provide an interpretation of whether the theory-based model being tested can be accepted directly or need modification, the researcher must direct his research to the predictive power of the model by observing the amount of residual produced [20].

\section{Analysis and Discussion of Research Results}

\subsection{Data Analysis}

Based on the results of the distribution of questionnaires it can be seen that the majority of respondents in this study had a high school education with 49 respondents (49\%). When viewed from the sex, most are women with a total of 60 respondents $(60 \%)$. Furthermore, the characteristics of respondents based on age, more dominated by respondents aged 31-35 with a number of 41 respondents (41\%).

Furthermore, data quality testing will be carried out by testing data normality, evaluating oulier, Multicollinierity and Singularity as well as the validity and reliability of the data to be presented as follows:
Table 1. Normality Test Results.

\begin{tabular}{|c|c|c|c|c|}
\hline Variable & $\min$ & $\max$ & kurtosis & c.r. \\
\hline Y9 & 2,000 & 5,000 &,- 370 &,- 756 \\
\hline $\mathrm{X} 15$ & 2,000 & 5,000 &,- 468 &,- 956 \\
\hline Y1 & 2,000 & 5,000 &,- 403 &,- 822 \\
\hline Y2 & 2,000 & 5,000 &,- 207 &,- 423 \\
\hline Y3 & 2,000 & 5,000 &,- 181 &,- 370 \\
\hline Y4 & 2,000 & 5,000 &,- 044 &,- 091 \\
\hline Y8 & 2,000 & 5,000 &, 270 &, 552 \\
\hline Y7 & 2,000 & 5,000 &,- 626 & $-1,277$ \\
\hline Y6 & 2,000 & 5,000 &,- 269 &,- 548 \\
\hline Y5 & 2,000 & 5,000 &,- 425 &,- 867 \\
\hline X11 & 2,000 & 5,000 &,- 022 &,- 046 \\
\hline $\mathrm{X} 12$ & 2,000 & 5,000 &,- 377 &,- 771 \\
\hline $\mathrm{X} 13$ & 2,000 & 5,000 & ,139 &, 285 \\
\hline X14 & 2,000 & 5,000 &,- 296 &,- 604 \\
\hline Z18 & 2,000 & 5,000 & ,680 & 1,388 \\
\hline $\mathrm{Z} 17$ & 3,000 & 5,000 &,- 825 & $-1,683$ \\
\hline Z16 & 3,000 & 5,000 &,- 352 &,- 719 \\
\hline $\mathrm{Z} 15$ & 2,000 & 5,000 &,- 175 &,- 356 \\
\hline Z11 & 3,000 & 5,000 &,- 453 &,- 924 \\
\hline Z12 & 2,000 & 5,000 &,- 179 &,- 365 \\
\hline Z13 & 2,000 & 5,000 &, 166 & ,338 \\
\hline Z14 & 2,000 & 5,000 & ,335 & ,684 \\
\hline Z45 & 2,000 & 5,000 & ,551 & 1,124 \\
\hline Z44 & 2,000 & 5,000 & ,673 & 1,373 \\
\hline Z43 & 2,000 & 5,000 &, 785 & 1,602 \\
\hline Z42 & 3,000 & 5,000 &, 694 & 1,417 \\
\hline Z41 & 2,000 & 5,000 & ,485 & ,990 \\
\hline Z54 & 2,000 & 5,000 &, 176 & ,360 \\
\hline Z53 & 2,000 & 5,000 & 2,032 & 4,149 \\
\hline Z52 & 2,000 & 5,000 & ,019 & ,039 \\
\hline Z51 & 2,000 & 5,000 & ,604 & 1,232 \\
\hline Z33 & 3,000 & 5,000 &,- 741 & $-1,512$ \\
\hline Z32 & 2,000 & 5,000 &, 142 & ,290 \\
\hline $\mathrm{Z} 31$ & 2,000 & 5,000 &,- 240 &,- 490 \\
\hline $\mathrm{Z} 23$ & 2,000 & 5,000 &,- 561 & $-1,144$ \\
\hline $\mathrm{Z} 22$ & 3,000 & 5,000 &,- 460 &,- 940 \\
\hline Z21 & 2,000 & 5,000 &, 335 &, 684 \\
\hline Multivariate & & & 33,152 & 3,085 \\
\hline
\end{tabular}

Source: Primary Data Processed, 2019

Test results show that the value of c.r. mutivariate is outside \pm 2.58 that means the normality assumption is not fulfilled. This phenomenon is not a serious problem as stated by Bentler \& Chou that if the estimation technique in the SEM model uses maximum likelihood estimation (MLE) even though the distribution of the data is not normal it can still produce a good estimate, so the data is feasible to be used in subsequent estimations [3].

Table 2. Outlier Test Results.

\begin{tabular}{lllll}
\hline Residuals Statistics $^{\mathbf{a}}$ & & & & \\
& Minimum & Maximum & Mean & Std. Deviation \\
\hline Predicted Value & 3,09 & 104,88 & 50,50 & 20,875 \\
Std. Predicted Value & $-2,271$ & 2,605 &, 000 & 100 \\
Standard Error of Predicted Value & 10,900 & 20,343 & 15,922 & 1,000 \\
\hline
\end{tabular}




\begin{tabular}{|c|c|c|c|c|c|}
\hline \multicolumn{6}{|l|}{ Residuals Statistics $^{\mathrm{a}}$} \\
\hline & Minimum & Maximum & Mean & Std. Deviation & $\mathbf{N}$ \\
\hline Adjusted Predicted Value & $-33,54$ & 126,90 & 50,31 & 26,132 & 100 \\
\hline Residual & $-44,868$ & 50,511 &, 000 & 20,147 & 100 \\
\hline Std. Residual & $-1,748$ & 1,968 &, 000 &, 785 & 100 \\
\hline Stud. Residual & $-2,368$ & 2,487 &, 002 & 1,009 & 100 \\
\hline Deleted Residual & $-82,349$ & 81,176 &, 187 & 33,745 & 100 \\
\hline Stud. Deleted Residual & $-2,465$ & 2,602 &, 005 & 1,023 & 100 \\
\hline Cook's Distance &, 000 &, 146 &, 018 &, 027 & 100 \\
\hline Centered Leverage Value &, 170 & ,618 &, 380 &, 089 & 100 \\
\hline
\end{tabular}

a. Dependent Variable: No

Source: Primary Data Processed, 2019

Outliers are observations or data that have unique characteristics that look very different from other observations and appear in the form of extreme values for a single variable or a combination variable [12]. Multivariate outliers were tested with Mahalanobis distance criteria at $\mathrm{p}$ $<0.001$. Distance is tested with Chi-Square $[\chi 2]$ on df for the number of independent variables $(\mathrm{df}=37)$. Conditions: if Mahalanobis $>$ of value $\chi 2$ is a multivariate outlier. Based on the table above, after testing it is known that the maximum MD value is 61.199 smaller than 69.334 . Therefore it was decided in the study that there were no outlier violations.

Next multicollinierity and singularity tests are performed. The decision making of this test is done by observing the Determinant covariance matrix, provided that if the determinant sample matrix approaches 0 (small), then there will be multicollinearity and singularity. Based on test results by using the AMOS 22.0 program, the results of the Determinant of Sample Covariance Matrix are $>0$, amounting to 379,292 , indicating no multicollinearity and singularity in this data so that the assumptions are met.

The next data quality test is testing the loading factor and Croncbach alpha values, as follows:

Table 3. Validity \& Reliability Testing Results.

\begin{tabular}{llll}
\hline Konstrak & Indicator & Loading factor & $\begin{array}{l}\text { Cronbach's Alpha } \\
\text { coefficient }\end{array}$ \\
\hline & $\mathrm{X} 11$ & 0,784 & \\
Health Promotion & $\mathrm{X} 12$ & 0,789 & 0,930 \\
(X1) & $\mathrm{X} 13$ & 0,849 & \\
& $\mathrm{X} 14$ & 0,928 & \\
& $\mathrm{X} 15$ & 0,898 & \\
& $\mathrm{Z} 11$ & 0,688 & \\
& $\mathrm{Z} 12$ & 0,755 & 0,925 \\
Perceived & $\mathrm{Z} 13$ & 0,807 & \\
Susceptibility & $\mathrm{Z} 14$ & 0,800 & \\
(Z1) & $\mathrm{Z} 15$ & 0,872 & \\
& $\mathrm{Z} 16$ & 0,827 & \\
& $\mathrm{Z} 17$ & 0,862 & \\
Perceived & $\mathrm{Z} 18$ & 0,605 & \\
Saverity (Z2) & $\mathrm{Z} 21$ & 0,848 & \\
& $\mathrm{Z} 22$ & 0,878 & \\
Perceived Benefit & $\mathrm{Z} 31$ & 0,926 & \\
(Z3) & $\mathrm{Z} 32$ & 0,916 & 0,892 \\
& $\mathrm{Z} 33$ & 0,775 & 0,891 \\
Perceived & $\mathrm{Z} 41$ & 0,679 & \\
Barriers (Z4) & $\mathrm{Z} 42$ & 0,640 & \\
\hline
\end{tabular}

\begin{tabular}{llll}
\hline Konstrak & Indicator & Loading factor & $\begin{array}{l}\text { Cronbach's Alpha } \\
\text { coefficient }\end{array}$ \\
\hline & Z44 & 0,895 & \\
& Z45 & 0,847 & \\
Cues to Action & Z51 & 0,868 & \\
(Z5) & Z52 & 0,799 & 0,896 \\
& Z53 & 0,829 & \\
& Y1 & 0,776 & \\
& Y2 & 0,807 & \\
& Y3 & 0,823 & \\
& Y4 & 0,880 & 0,961 \\
Self-Efficacy (Y) & Y5 & 0,866 & \\
& Y6 & 0,892 & \\
& Y7 & 0,881 & \\
& Y8 & 0,809 & \\
& Y9 & 0,846 & \\
& & eliminated & \\
\hline
\end{tabular}

Source: Primary Data Processed, 2019

Based on the results of confirmatory factor analysis, it can be seen that the factor loadings of each indicator questions that make up each variable are mostly $\geq 0.5$, so that the instrumentation indicators for each construct can be said to be of good enough validity and can be accepted. While the results of internal consistency reliability testing for each of the variables above shows good results where the Cronbach's Alpha coefficient obtained entirely meets the required rules of thumb, which is $\geq 0.7$ [12].

If all of the data quality tests have been declared to meet the requirements then a further model and causality test will be further explained as follows:

1. Model Testing

In the SEM model, the measurement model and the structural model the parameters are estimated together. This method has a little difficulty in meeting the demands of the model fit. The biggest possibility is caused by the interaction between measurement model and structural model which are estimated together (One Step Approach to SEM). One step aprroach to SEM is used if the model is believed to be based on a strong theory and the validity $\&$ reliability of the data is very good. The results of estimation and fit of the one step approach to SEM models using the Amos 22.0 application program are shown in the Goodness of Fit Figure and Table below. 


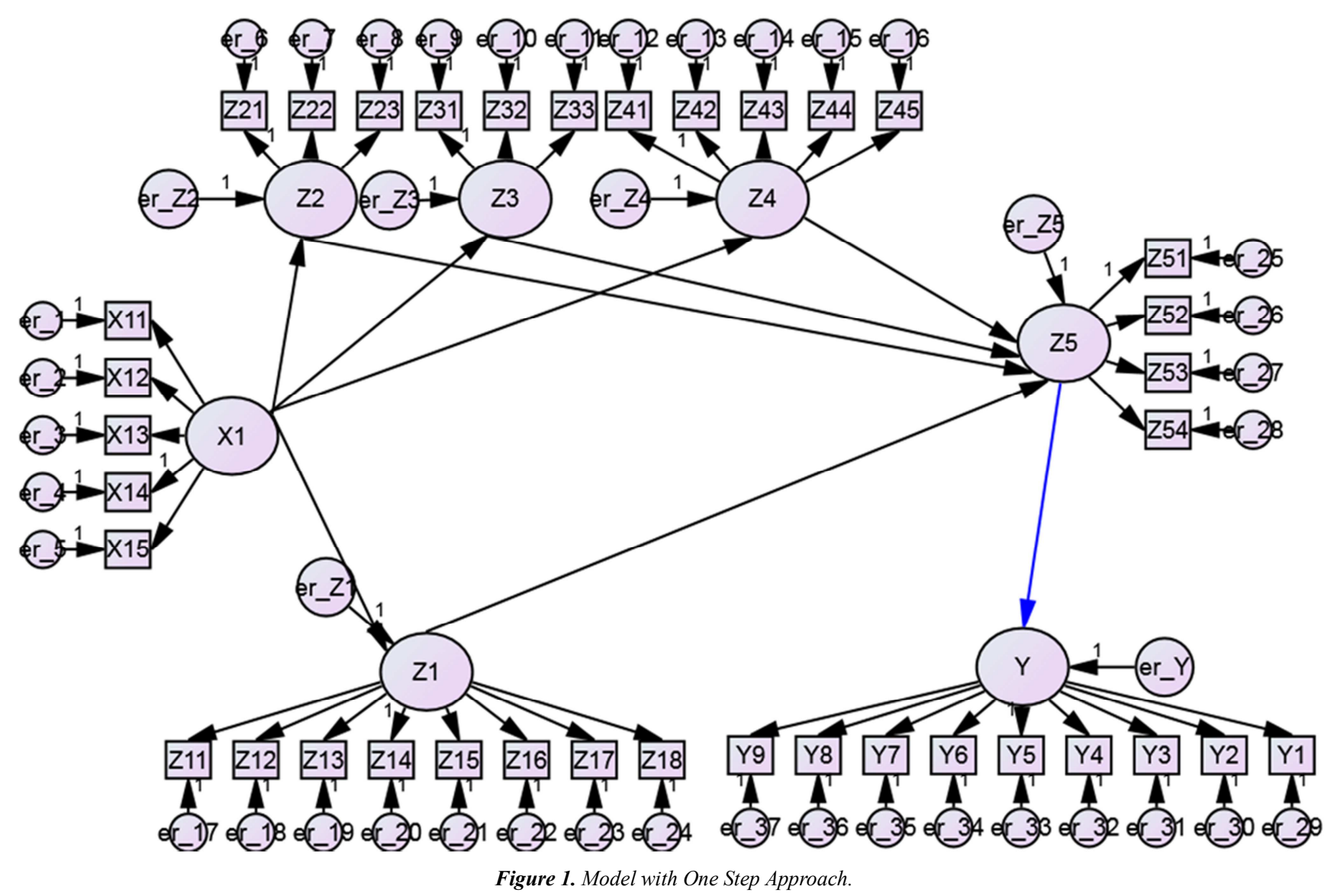

Table 4. Evaluate the Goodness of Fit Indices Criteria.

\begin{tabular}{llll}
\hline Criteria & Result & Critical Value & Model Evaluation \\
\hline Cmin/DF & 1,229 & $\leq 2,00$ & Fit \\
Signifikansi & 0,000 & $\geq 0,05$ & Not fit \\
RMSEA & 0,028 & $\leq 0,08$ & Fit \\
GFI & 0,863 & $\geq 0,90$ & Marginal \\
AGFI & 0,838 & $\geq 0,90$ & Marginal \\
TLI & 0,977 & $\geq 0,95$ & Fit \\
CFI & 0,980 & $\geq 0,94$ & Fit \\
\hline
\end{tabular}

Source: Primary Data Processed, 2019

From the results of the evaluation of the one step approach model, it turns out that of all the goodness of fit criteria used, most of them showed the results of a good model evaluation, meaning the model was in accordance with the data. That is, the conceptual model developed and based on theory has been fully supported by facts. Thus this model is the best model to explain the relationship between variables in the model in this study.

2. Causality Testing

Looking at the determinant of sample covariance matrix numbers: $379,292>0$ indicates that there is no multicolinierity or singularity in this data so that the assumptions are met. Thus the magnitude of the regression coefficients of each factor can be trusted as seen in the causality test below:
Table 5. Causality Test Results.

\begin{tabular}{|c|c|c|c|c|c|}
\hline \multicolumn{3}{|c|}{ Regression Weights } & \multirow{2}{*}{$\begin{array}{l}\text { Ustd } \\
\text { Estimate }\end{array}$} & \multirow{2}{*}{$\begin{array}{l}\text { Std } \\
\text { Estimate }\end{array}$} & \multirow{2}{*}{ Prob. } \\
\hline Faktor & $\Rightarrow$ & Faktor & & & \\
\hline $\mathrm{X}_{1}$ & $\Rightarrow$ & $Z_{1}$ & 0,187 & 0,296 & 0,005 \\
\hline $\mathrm{X}_{1}$ & $\Rightarrow$ & $\mathrm{Z}_{2}$ & 0,504 & 0,753 & 0,000 \\
\hline $\mathrm{X}_{1}$ & $\Rightarrow$ & $\mathrm{Z}_{3}$ & 0,559 & 0,702 & 0,000 \\
\hline $\mathrm{X}_{1}$ & $\Rightarrow$ & $\mathrm{Z}_{4}$ & 0,233 & 0,460 & 0,000 \\
\hline $\mathrm{Z}_{1}$ & $\Rightarrow$ & $\mathrm{Z}_{5}$ & $-0,048$ & $-0,039$ & 0,509 \\
\hline $\mathrm{Z}_{2}$ & $\Rightarrow$ & $\mathrm{Z}_{5}$ & 0,207 & 0,176 & 0,015 \\
\hline $\mathrm{Z}_{3}$ & $\Rightarrow$ & $\mathrm{Z}_{5}$ & $-0,074$ & $-0,075$ & 0,290 \\
\hline $\mathrm{Z}_{4}$ & $\Rightarrow$ & $\mathrm{Z}_{5}$ & 1,395 & 0,898 & 0,000 \\
\hline $\mathrm{Z}_{5}$ & $\Rightarrow$ & $\mathrm{Y}$ & 0,588 & 0,517 & 0,000 \\
\hline \multicolumn{5}{|c|}{ Limits of Significance } & $\leq 0,05$ \\
\hline
\end{tabular}

Information:

$\mathrm{X} 1=$ Health Promotion

$\mathrm{Z} 1$ = Perceived Susceptibility

$\mathrm{Z} 2$ = Perceived Severity

Z3 = Perceived Benefits

$Z 4=$ Perceived Barriers

$\mathrm{Z5}=$ Cues to action

$\mathrm{Y}=$ Self-efficacy

Judging from the level of probability of the causal relationship, the hypothesis which states that:

1. The Health Promotion (X1) variable influences the Perceived Susceptibility (Z1), is unacceptable (the probabilities are $0.005 \leq 0.05$ (significant).

2. The Health Promotion (X1) variable influences the Perceived Severity (Z2) variable, it can be accepted (the causal probability is $0,000 \leq 0.05$ (significant). 
3. The Health Promotion (X1) variable has an effect on Perceived Benefits (Z3), it can be accepted (Probably causal $0,000 \leq 0.05$ (significant).

4. The Health Promotion (X1) variable influences the Perceived Barriers (Z4) variable, it can be accepted (the causal probability is $0,000 \leq 0.05$ (significant).

5. The Perceived Susceptibility (Z1) variable influences the Cues to action (Z5) variable, unacceptable, Prob. the cause is $0.509 \geq 0.05$ (not significant).

6. Perceived Severity (Z2) variable influences Cues to action (Z5) Variable, acceptable, Prob. the cause is $0.015 \leq 0.05$ (significant).

7. Variable Perceived Benefits (Z3) affect Cues to action Variable (Z5), unacceptable, Prob. the cause is $0.290 \geq$ 0.05 (not significant).

8. The Perceived Barriers (Z4) variable influences the Cues to action (Z5) variable, acceptable, Prob. the cause is $0,000 \leq 0.05$ (significant).

9. Cues to action variable (Z5) influences the Selfefficacy (Y) variable, acceptable, Prob. the cause is $0,000 \leq 0.05$ (significant).

\subsection{Discussion}

\subsubsection{Effect of Health Promotion on Perceived Susceptibility}

The results of testing this study indicate that health promotion has a significant effect on perceived susceptibility. This result is shown by the probability value obtained at 0.005 where the value is greater than the specified cut-off value of 0.05 . These results indicate that health promotion carried out by the Health Office and the Government of Kediri Regency through its health workers, can not significantly influence the perception of the vulnerability of pregnant women. For this reason, a common thread can be drawn that the hypothesis that there is an influence of health promotion on the perceived susceptibility of pregnant women in Kediri cannot be proven true.

The ineffectiveness of health promotion can be due to the diversity of levels of understanding from the community, be it the family or closest people of pregnant women or pregnant women themselves in digesting messages or information on health promotion programs delivered by stakeholders or health workers. So that the knowledge and information conveyed by stakeholders and health workers cannot be understood properly by the community which in this case is the family or the closest person to the pregnant mother and the pregnant mother herself. So that the health promotion activities undertaken have not been able to help form a strong perception in the minds of the community, so they can behave to reduce health risks that threaten him.

Through this circumstance, it is suspected that the health promotion model needed by the people of Kediri Regency is in addition to media promotion and outreach in general, there is also a need for two-way communication through interactive dialogue between stakeholders, health workers and the community. Given the different levels of understanding and mindset. Through these personal approaches it is expected to illustrate how the risks and vulnerabilities that will occur if not behave in a healthy life.

The results of this study are supported by the opinion expressed by Gumilang \& Wulandari which in his research stated that the planning of the PKRS unit had not been prepared properly as regulated in the regulations [11]. There is no strategic planning or operational planning. PKRS Unit does not yet have a systematic and structured organization. Human resource qualifications in general are eligible, but need additional quantities. The PKRS unit has no special health promotion for health workers so what is promoted will be difficult to influence the perception of human vulnerability to the disease, which this has little in common with this study.

In addition, these results are also supported by research conducted by Nurdiana, where in the research results it is stated that the Airlangga University hospital already has a PKRS unit that has carried out health promotion on the inside and outside of the building, but this PKRS unit does not yet have a promotional study health such as holding FGDs with patients, patients' families and hospital visitors, so this also shows that with such conditions it is possible that health promotion cannot significantly influence perceptions of vulnerability [17].

\subsubsection{Effect of Health Promotion on Perceived Severity}

The results of testing this study indicate that health promotion has a significant effect on perceived severity. This result is shown by the probability value obtained at 0,000 where the value is smaller than the specified cut-off value of 0.05 . These results indicate that health promotion carried out by the Health Office and the Government of Kediri Regency through its health workers, can significantly affect the perceived saverity or perception of the seriousness of a mother's pregnancy conditions. For this reason, a common thread can be drawn that the hypothesis that there is an influence of health promotion on the perceived saverity of pregnant women in Kediri can be proven true.

This can be because through promotional media made by stakeholders and health workers, especially those that are audio visual such as public service announcements, pamphlets and other images are basically able to give the impression of perception in the minds of the public about the seriousness of the condition of pregnant women if not treated properly, especially pregnant women who have a history of certain diseases or because of age.

The results of this study are supported by opinions expressed by Wibawati et al who in their research showed results in which health promotion can influence perceptions of the seriousness of the condition of pregnant women. This is reflected in the results of his research which states that Dinoyo Community Health Center is quite total in conducting health promotion, where in its implementation it uses an empowerment strategy, community development and advocacy supported by promotional media. The implementation of health promotion at the Dinoyo Community Health Center was supported by special health 
promotion officers who received training for health promotion and supporting media for results from the health center staff. The support from professional and competent staffs will be able to open the horizon of pregnant women, that their current condition needs to get serious attention in order to prevent the occurrence of maternal and infant deaths, even though at present he has no history of any disease. Likewise with the health workers who handle and examine it, must carry out their duties in accordance with the SOP and be responsive [25].

Not much different from the previous opinion, Pratiwi et al also found results in her research that support the results of this study, namely health promotion can affect the perceived saverity or perception of the seriousness of the condition of pregnant women. In the research of Pratiwi et al it was mentioned that the role of puskesmas health promotion in the achievement of healthy living behavior can be realized through a series of health promotion programs namely home visits, empowerment through partnerships, and organizing through Community Based Health Efforts (UKBM), through these activities expected to arouse awareness of pregnant women to apply healthy behavior patterns and be aware of the seriousness of their conditions during pregnancy [21].

\subsubsection{Effect of Health Promotion on Perceived Benefits}

The results of testing this study indicate that health promotion has a positive and significant effect on perceived benefits. This result is shown by the probability value obtained at 0,000 where the value is smaller than the specified cut-off value of 0.05 . These results indicate that health promotion carried out by the Health Office and the Government of Kediri Regency through its health workers, can significantly affect the perceived benefits or perceived benefits of pregnant women if they obtain information on maternal and infant health and the condition of a mother's pregnancy from the health promotion program the. For this reason, a common thread can be drawn that the hypothesis that there is an influence of health promotion on the perceived benefits of pregnant women in Kediri can be proven true.

This is because in the health promotion program conducted by Kediri District, the promotional content has been accompanied by information about the benefits if the community adopts a healthy lifestyle, so that in general it has been able to build perceptions of the perceived benefits when implementing a healthy lifestyle behavior.

The results of this study are supported by the opinion expressed by Setyabudi \& Dewi which states that health promotion activities carried out through an appropriate strategy, approach and method, will be able to change people's perceptions from the beginning who regard it as a wind and then to no avail. In vain, it becomes something that is needed and always looked forward to. This happened at Dr. Mental Hospital RM. Soeedjarwadi, Central Java Province, which has implemented a well-targeted and well-targeted health promotion strategy. The first strategy is advocacy in the form of political lobbying, seminars and / or media presentations and advocacy. Second, social support where the strategy is referred to as developing the atmosphere or fostering a conducive atmosphere. Establishment of this atmosphere is divided into three forms, namely the development of the individual atmosphere, the development of the atmosphere of society and the atmosphere of society. Third, community empowerment which is the process of providing information to groups, families and individuals continuously. With a health promotion strategy, it will help the hospital to realize and increase health awareness in people's lives [21].

\subsubsection{Effect of Health Promotion on Perceived Barriers}

The results of testing this study indicate that health promotion has a significant effect on perceived barriers. This result is shown by the probability value obtained at 0,000 where the value is smaller than the specified cut-off value of 0.05 . These results indicate that health promotion carried out by the Health Office and the Government of Kediri Regency through its health workers, can significantly affect the perceived barriers or individual evaluations of the obstacles encountered to adopt the recommended health behavior. For this reason, a common thread can be drawn that the hypothesis that there is an influence of health promotion on perceived barriers of pregnant women in Kediri can be proven true.

Health promotion carried out by the Kediri Regency which is supported by mass media, print media and online media has generally been dissertated with a variety of depictions and illustrations, so that people who see or follow and know the health promotion program, will certainly get a description of what should be done. From this description then arises the process of analysis in the minds of the community and identification of what are obstacles to him in adopting healthy behavior patterns.

The results of this study are supported by the opinion expressed by Sulistiawan et al which states that health promotion will be something that is missed by the community when the promotion is carried out giving value inherent in the minds of the community itself. One of the values that can be attached is information that is very useful for the recipient, such as how to apply a healthy lifestyle that is good and right, as well as what obstacles will be faced and how to overcome if encountered these obstacles. The results of Sulistiawan et al's research conducted in the Dolly Localization Area of Surabaya City showed a fact that the key point for the success of the health promotion program was the involvement of the empowerment subject in every decision making aimed at generating internal motivation so that the subject made the empowerment program a necessity [22].

\subsubsection{The Effect of Perceived Susceptibility on Cues to Action}

The test results of this study indicate that perceived susceptibility does not significantly influence cues to action. This result is shown by the probability value obtained at 0.509 
where the value is greater than the specified cut-off value of 0.05 . These results indicate that the perceived susceptibility or perception of the vulnerability of maternal pregnancy cannot influence Cues to Action or cues to take action. For this reason, a common thread can be drawn that the hypothesis that the effect of perceived susceptibility on cues to action of pregnant women in Kediri cannot be proven true.

That is because at this time the perception of vulnerability that is owned by the community, especially families, pregnant women and the closest people around pregnant women is still dominated by many of the beliefs and culture inherited from previous people. So even if someone is pregnant, or those who are caring for or accompanying pregnant women know or even feel there are health problems when they are pregnant, they will not necessarily be motivated to seek medical help, but rather first ask the experiences of people beforehand. Only after that if there is no change, will take the medical route. However, when the constraints can be solved alternatively or traditionally, then the solution is sufficient.

The results of this study reject the opinion expressed by Mohsen et al which states that the application of the Health Belief Model has proven to be able to effectively change people's beliefs in adopting healthy living behaviors [14].

\subsubsection{Effect of Perceived Severity on Cues to Action}

The test results of this study indicate that perceived severity has a significant effect on cues to action. This result is shown by the probability value obtained at 0.015 where the value is smaller than the specified cut-off value of 0.05 . These results indicate that the perceived severity of pregnant women has a significant effect on Cues to Action. For this reason, a common thread can be drawn that the hypothesis that there is an influence of perceived severity on the cues to action of pregnant women in Kediri can be proven true.

This can be caused because when someone already has the perception that pregnancy is not a disease, but from a pregnancy will be able to cause illness and new diseases, then obviously someone considers that this pregnancy is something serious. That way something serious and categorized as urgent will encourage someone to take immediate action to minimize all the risks, with the aim of not threatening the pregnancy of a mother and even her baby.

The results of this study are supported by the opinion expressed by Nagshpour which states that HBM construction, including perceptions of vulnerability, perceived severity, perceived benefits, and perceived obstacles can increase knowledge, attitudes, and practices related to calcium intake among teenage students [15].

\subsubsection{Effect of Perceived Benefits on Cues to Action}

The test results of this study indicate that perceived benefits do not have a significant effect on cues to action. This result is shown by the probability value obtained by 0.290 where the value is greater than the specified cut-off value of 0.05 . These results indicate that perceived benefits of pregnant women do not affect Cues to Action or cues to take action. For this reason, a common thread can be drawn that the hypothesis that there is an effect of perceived benefits on cues to action of pregnant women in Kediri cannot be proven true.

When the public or pregnant women have realized that the precautions they have taken provide benefits or benefits to their health conditions, but on the other hand, policies and assistance from the government which were initially considered very helpful are complex and difficult to access, then the choice immediately falls on the actions the economical one. Like when through a health promotion activity a pregnant woman has realized the importance of prioritizing her pregnancy in midwives or other health workers, even the government provides assistance and facilities for the underprivileged people through the JAMPERSAL program (childbirth assurance), but at the time of implementation there are complaints in terms of complicated service and administration., ultimately, makes people reluctant to use the service and prefers alternative procedures. The results of this study are supported by the opinion expressed by Nagshpour which states that HBM construction, including perceptions of vulnerability, perceived severity, perceived benefits, and perceived obstacles can increase knowledge, attitudes, and practices related to calcium intake among teenage students [15].

\subsubsection{The Effect of Perceived Barriers on Cues to Action}

The test results of this study indicate that perceived barriers have a significant effect on cues to action. This result is shown by the probability value obtained at 0,000 where the value is smaller than the specified cut-off value of 0.05 . These results indicate that perceived barriers of pregnant women have a significant effect on Cues to Action. For this reason, a common thread can be drawn that the hypothesis that there is an effect of perceived barriers on cues to action of pregnant women in Kediri can be proven true.

Someone who perceives that to follow the pattern of healthy living behavior is not an easy matter and can be done just like that, then he will tend not to stand idle and just stay quiet. He will be stimulated to take a preventive action in order to be able to do a healthy lifestyle.

This shows that the perception of obstacles that will be experienced by pregnant women during the process of pregnancy and childbirth later, will determine the choice of action to be taken. The results of this study are supported by the opinion expressed by Nagshpour which states that HBM construction, including perceptions of vulnerability, perceived severity, perceived benefits, and perceived obstacles can increase knowledge, attitudes, and practices related to calcium intake among teenage students [15].

\subsubsection{Effect of Cues to Action on Self-efficacy}

The test results of this study indicate that cues to action have a significant effect on self efficacy. This result is shown by the probability value obtained at 0,000 where the value is smaller than the specified cut-off value of 0.05 . These results indicate that cues to action for pregnant 
women have a significant effect on self-efficacy or the belief of pregnant women regarding their ability to look after their pregnancies and to deliver safely to both mothers and babies. For this reason, a common thread can be drawn that the hypothesis that there is an influence of cues to action on self-efficacy of pregnant women in Kediri can be proven true.

This shows that family experiences and personal experiences will determine the next steps that must be taken by pregnant women. However, instincts and self-belief that will be able to be the right choice. In choosing how to take care during pregnancy and like where you will deliver later, it must be from your own conscience, others including your husband may give advice and consideration, but the mentality of the pregnant woman is only herself who decides. A pregnant woman must be confident in her physical abilities and endurance, choosing a path that minimizes risk and has the right to receive the best possible service and treatment with the ultimate goal being the safety and health of the mother and baby.

The results of this study are supported by the opinion expressed by Nagshpour which states that HBM construction, including perceptions of vulnerability, perceived severity, perceived benefits, and perceived obstacles can increase knowledge, attitudes, and practices related to calcium intake among teenage students [15].

\section{Finality}

\subsection{Conclusion}

1. Health promotion has a significant effect on perceived susceptibility.

2. Health promotion has a significant effect on perceived severity.

3. Health promotion has a positive and significant effect on perceived benefits.

4. Health promotion has a significant effect on perceived barriers.

5. Perceived susceptibility has no significant effect on cues to action.

6. Perceived severity has a significant effect on cues to action.

7. Perceived benefits do not have a significant effect on cues to action.

8. Perceived barriers have a significant effect on cues to action.

9. Cues to action have a significant effect on self efficacy.

\subsection{Suggestion}

Based on the conclusions obtained, the following suggestions can be made:

1. This research is expected to be able to add to the treasury of social-based theoretical social sciences based on health promotion aimed at providing education to the public and especially pregnant women, which will change previous behavior based on ancestral culture and beliefs which are inherited down and down, leading to patterns of behavior. healthy life by considering aspects in the Health Belief Model (HBM) component

2. This research is expected to be able to add to the treasury of social-based theoretical social sciences based on health promotion aimed at providing education to the public and especially pregnant women, which will change previous behavior based on ancestral culture and beliefs which are inherited down and down, leading to patterns of behavior. healthy life by considering aspects in the Health Belief Model (HBM) component

\section{References}

[1] Adejoh, S. O., 2014. Diabetes Knowledge, Health Belief, and Diabetes Management Among the Igala. SAGE, 1 (1), pp. 1-8.

[2] Adima, F., 2017. Profil Kesehatan Kota Kediri Tahun 2017. Pertama penyunt. Kediri: Dinas Kesehatan Kabupaten Kediri.

[3] Bentler, P. M. \& Chou, C. P., 1987. Practical Issues In Structural Modelling. Sociological Methods \& Research, 1 (6), pp. 78-117.

[4] BPHP UMY, 2010. Promosi Kesehatan di Indonesia Kurang Maksimal. [Online] Available at: http://www.umy.ac.id/promosi-kesehatan-di-indonesiakurang-maksimal.html

[5] Conner, M. \& Norman, P., 2005. Predicting Health Behavior. 2nd penyunt. London: Open University Press.

[6] Dachroni, J., 2003. Promosi Kesehatan Penanggulangan Masalah Rokok. Jakarta: Interaksi Media Promosi Kesehatan Indonesia Nomor XIV.

[7] DINKES, K. K., 2015. Keberhasilan Penurunan AKI dan AKB Kabupaten Kediri. [Online] Available at: http://www.dinkes.kedirikab.go.id/?hal=dbet\&id=72

[8] Ersin, F. \& Bahar, Z., 2011. Effect of Health Belief Model and Health Promotion Model on breast cancer early diagnosis behavior: A systematic review. Asian Pacific Journal of Cancer Prevention, 1 (2), pp. 2555-2562.

[9] Galanz, K. R., Barbara, K. \& Viswanath, K., 2008. Health Behaviour And Health Education Theory, Research, And Practice 4th. San Fransisco: Jossey Bass.

[10] Green, L. W. \& Kreuter, 2005. Health Program Planning. An. Educational Ecological Approach. New York: The MeGrawHill Companies. Inc.

[11] Gumilang, B \& Wulandari, R, D, 2016. Rencana Implementasi Kebijakan Promosi Kesehatan di Rumah Sakit Universitas Airlangga. Jurnal Administrasi Kesehatan Indonesia, 4 (1), 48-56.

[12] Hair, J. F. J., Anderson, R. E., Tatham, R. L. \& Black, W. C., 1998. Multivariate Data Analysis. Upper Saddle River: Prentice Hall.

[13] Laksono, A., 2016. Profil Kesehatan Kabupaten Kediri, Kediri: Dinas Kesehatan Pemerintah Kabupaten Kediri. 
[14] Mohsen, M, M., El-Abbassy, A, A., \& Khalifa, A, M., 2016. Effect of Application of a Health Belief Model on Changing Mothers' Beliefs Regarding Birth Spacing in Rural Areas, Clinical Nurse Studies, 4 (3), 54-66.

[15] Nagashphour, M., Shakerinejad, G., Lourizadeh, M, R., Hajinajah, S., \& Jarvandi, F., 2014. Nutrititon Education Based on Health Belief Model Improves Dietary Calcium Intake Among Female Student of Junior High Schools, J Health Popul Nutr, 32 (3), 420-429.

[16] Notoatmodjo, S., 2007. Promosi Kesehatan dan Ilmu Perilaku. Jakarta: PT. Rineka Cipta.

[17] Nurdiana, F., 2017. Pelaksanaan Promosi Kesehatan di Rumah Sakit Universitas Airlangga, Jurnal Promkes, 5 (2), 217-231.

[18] Onoruoiza, S. I., Musa, A., Umar, B. D. \& Kunle, Y. S., 2015. Using Health Belief Model as an Intervention to Non Compliance with Hypertension Information among Hypertensive Patient. International Organization of Scientific Research Journal Of Humanities And Social Science, 20 (9), pp. 11-16.

[19] Priyoto, 2014. Teori Sikap dan Perilaku dalam Kesehatan Dilengkapi dengan Contoh Kuesioner. Yogyakarta: Nuha Medika.
[20] Santoso, S., 2015. Amos 22 Untuk Struktural Equation Modelling - Konsep Dasar dan Aplikasi. Jakarta: PT. Elex Media Komputindo.

[21] Setyabudi, R, G., \& Dewi, M., 2017. Analisis Startegi Promosi Kesehatan dalam Rangka Meningkatkan Kesadaran Hidup Sehat oleh Rumah Sakit Jiwa Daerah Dr. RM. Soedjarwadi Provinsi Jawa Tengah. Jurnal Komunikasi, 12 (1), 2548-7647.

[22] Sulistiawan, D., Hakim, L., \& Hargono, R., 2014, Pendidikan Kesehatan Reproduksi Remaja Melalui Pemberdayaan Pendidik Sebaya di Kawasan Lokalisasi Dolly Kota Surabaya. Jurnal Promkes, 2 (2), 140-147.

[23] Susilowati, D., 2016. Promosi Kesehatan. Jakarta: Pusdik SDM Kesehatan.

[24] WHO, 1986. The Ottawa Charter for Health Promotion. [Online] Available at: http://www.who.int/health promotion/conferences/previous/Ottawa/en/

[25] Wibawati, P, I., Zauhar, S \& Riyanto, Z., 2011. Implementasi Kebijakan Promosi Kesehatan (Studi Pada Pusat Kesehatan Masyarakat Dinoyo, Kecamatan Lowokwaru, Kota Malang). 